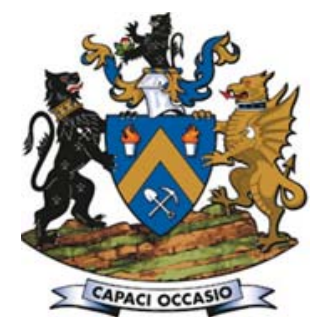

\title{
Separation of kimberlite from waste rocks using sensor-based sorting at Cullinan Diamond Mine
}

\author{
by T. Mahlangu*`, N. Moemise ${ }^{\dagger}$, M.M. Ramakokovhu*, \\ P.A. Olubambi ${ }^{\ddagger}$, and M.B. Shongwe* \\ Paper written on project work carried out in partial fulfilment of B'Tech. Eng. \\ (Metallurgical Engineering)
}

\section{Synopsis}

Near-infrared (NIR) spectroscopy sorting technology is incorporated in an automated optical mineral sorter that can discriminate between materials using the differences in characteristics when exposed to near-infrared radiation. During September 2014 to April 2015, a pilot plant that utilized NIR technology to discriminate between kimberlite and waste materials was commissioned to determine the viability of including this technology in the diamond winning process flow sheet at Cullinan Diamond Mine. The plant was used to minimize the waste content in the size fraction $-70+35$ $\mathrm{mm}$ that reports to the crushing section and then to the dense media separation process. This paper describes the initial test work, conducted at Mintek, that led to the decision to conduct a pilot-scale study. The mineralogical characterization of the feed and product streams to establish the sorting criteria and the operational data obtained during the pilot plant campaign are described. The results indicated a good possibility of discriminating between the kimberlite and waste material using NIR technology. However, the consistency of discrimination was not good enough to avoid the risk of potential diamond loss. Furthermore, a lower than expected availability of the machine reduced the throughput capabilities.

Keywords

sensor-based sorting, NIR spetroscopy, kimberlite, preconcentration.

\section{Introduction}

Using near-infrared spectroscopy (NIRS) technology for ore sorting is a new concept for the mineral processing and mining industry. NIRS has been used for decades in the laboratory for the identification of pure minerals, and has its roots in the recycling, food, and pharmaceutical industries (Salter and Wyatt, 1991; Robben et al., 2009). Ore sorting in itself is not a new concept; it was introduced during the Stone Age with handsorting being the first method to separate valuable materials from gangue (Wills and Napier-Munn, 2006; Sassos, 1985). However, over the years the scale of mining has increased and hand-sorting has become challenging to implement (Joensson, 2014).

Sensor-based sorting is an advanced technology that can help overcome problems such as ore dilution experienced in mineral processing operations. The benefits are lower energy and water costs, reduced ore dilution, lower environmental impact, and improved profit margin (Mathew, 1974; Jonsson, 2014;
Salter and Wyatt, 2009; Death et al., 2009). In sensor-based sorting, materials are mechanically sorted based on certain physical properties that are detected by a sensor (Dalm, 2013). Research has found that with NIR scanners it is possible to obtain a 'fingerprint' of a sample that is directly related to its mineralogical composition. According to Woutruba et al. (2009), molecules absorb NIR radiation by means of electronic and vibrational transitions. Nowadays, there are many sensors available in the market that utilize different material properties; the choice of a sensor is dependent on the mineralogy of the ore.

Traditional metallurgical techniques for diamond winning from kimberlitic ore involve size reduction, dense medium separation (DMS), and final recovery by X-ray technology (Ketelhodt et al., 2013). These techniques have no ability to remove waste rocks that are often associated with the kimberlite. The kimberlite orebody at Cullinan Diamond Mine (CDM) is intruded by sills and dykes of waste rock, and the current mining method cannot separate the waste material (Bartlett, 1994). Waste hoisted from underground is mostly from development areas. This paper evaluates the viability of the new COLOR/NIR sorting technology to remove the waste rocks from the kimberlite ore stream, thus reducing the amount of waste going into the DMS process.
* Institute for NanoEngineering Research, Department of Chemical, Metallurgical and Materials Engineering, Tshwane University of Technology, Pretoria, South Africa.

$\dagger \quad$ Cullinan Diamond Mine, Petra Diamonds Southern Africa (Pty) Ltd.

\$ Department of Chemical Engineering Technology, University of Johannesburg, Johannesburg, South Africa.

(C) The Southern African Institute of Mining and Metallurgy, 2016. ISSN 2225-6253. Paper received Feb. 2016. 


\section{Separation of kimberlite from waste rocks using sensor-based sorting}

\section{Experimental procedures}

\section{Material characterization}

In order to provide background information for sensor-based sorting, mineralogical characterization of a run of mine (ROM) sample from CDM was performed by X-ray diffraction (XRD). The primary use of XRD is for the identification and characterization of compounds based on their diffraction patterns.The sample, which had a top size of $-70 \mathrm{~mm}$, was reduced using a single toggle jaw crusher followed by ball milling. The XRD results are shown in Figure 1 and Figure 2.

Both the kimberlite (Figure 1) and the waste (Figure 2) were found to contain NIR-active minerals, and there is thus the possibility of using NIR technology to discriminate between the two streams. Images (Figure 3) extracted from the classifier also showed a very good possibility of separating kimberlite from the associated waste materials. Classifiers are part of the NIR technology programme and are used to classify materials (Korsten, 2014).

\section{Preliminary ore sorting studies}

Tests work was conducted with the Pro Secondary COLOR/NIR sorter illustrated in Figure 4. The sorter uses a combination of a high-resolution line camera and NIR scanner to provide accurate detection of the mineral fingerprint of each rock (Ketelhodt et al., 2013). The working width of the COLOR/NIR sorter is $1200 \mathrm{~mm}$.

The technical set-up of the sorter is shown in Figure 5. The sorter used was a chute-type sorter, with the material fed by a vibratory feeder and accelerated down a chute under gravity. Scanning is done by means of an NIR and a colour sensor on the free-falling stream of particles. Prior to the sorter, a washing/sizing screen with a $10 \mathrm{~mm}$ aperture size was installed for the purpose of particle preparation. Sizing was done to obtained a size ratio of $1: 3$, because research on

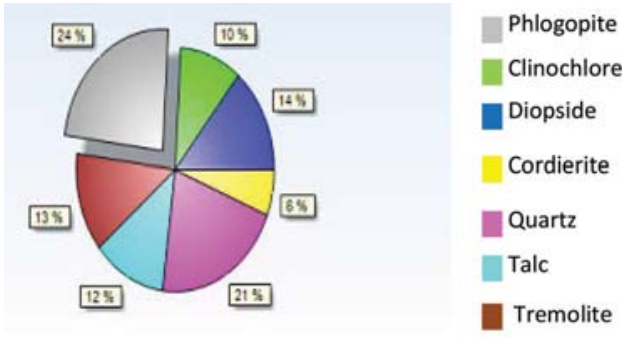

Figure 1-XRD mineralogical characterization of kimberlite

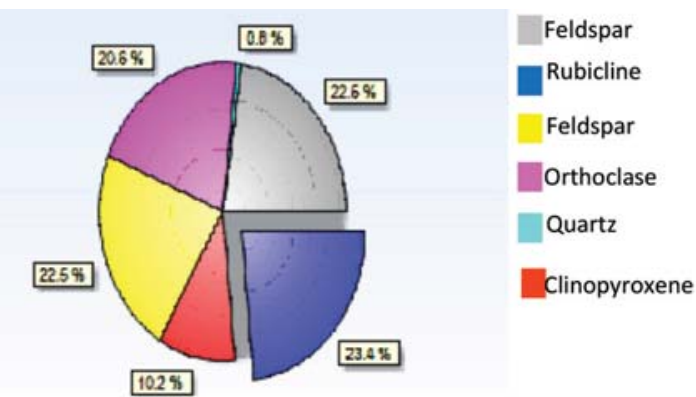

Figure 2-XRD mineralogical characterization felsite (waste) (a)

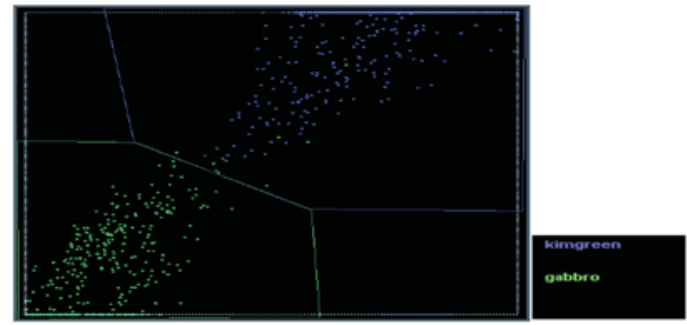

(b)

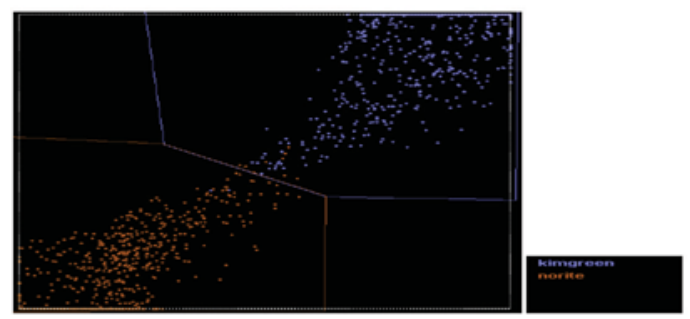

(c)
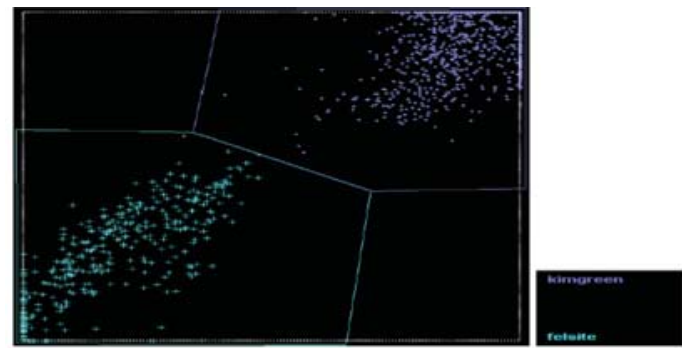

Figure 3-Images from the NIR sorter classifier showing discrimination between kimberlite and (a) gabbro, (b) norite, and (c) felsite

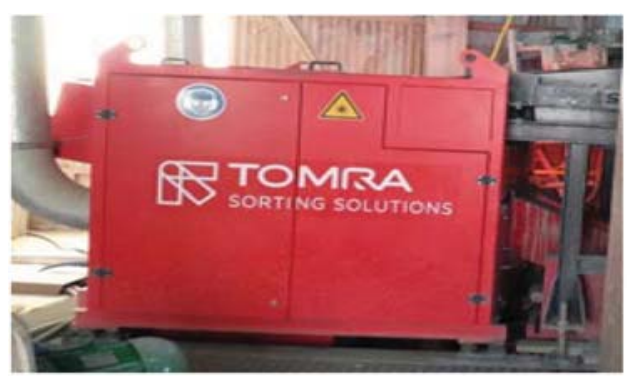

Figure 4-Pro Secondary COLOR/NIR sorter from Tomra Sorting Solutions

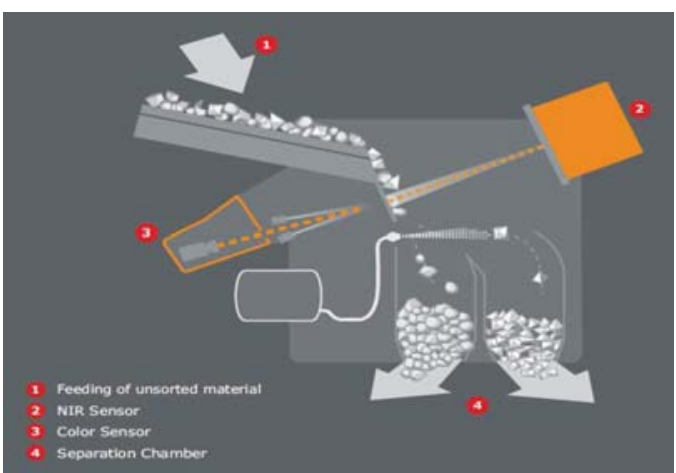

Figure 5-Technical set-up of the COLOR/NIR sorter (Ketelhodt et al., 2013) 


\section{Separation of kimberlite from waste rocks using sensor-based sorting}

sensor based technology has shown that the sorting results can deteriorate at a particle size ratio greater than three (Woutruba and Riedel, 2005).

The material that was supplied for the test work was a $12 \mathrm{t}$ sample of Cullinan ROM material. The waste rocks at CDM comprise of gabbro, norite, felsite, and quartzite. The sample, which was collected by means of a belt cut, was within the size range of $-70+35 \mathrm{~mm}$. The sorter needs to be programmed with information obtained from a pre-classified sample. Thus, a $10 \mathrm{~kg}$ sample of the kimberlites and waste material was collected from underground at Cullinan. Groups were formed by statistical means and applied into the sorting algorithm, called the classifier, for bulk sorting. The process flow diagram configuration shown in Figure 6 was tested with the aim of maximizing overall kimberlite recovery with a target of $5 \%$ kimberlite loss to the waste stream.

\section{Preliminary ore sorting results}

\section{Rougher stage}

The overall results of the tests that were carried out only in the rougher stage are shown in Table I and Figure 7. The average kimberlite recovery was calculated to be $97.8 \%$, while the average waste removal was calculated to be $90.2 \%$

\section{Scavenger stage}

The scavenger stage was used to recover the kimberlite misclassified into the waste stream from the rougher stage. Approximately $4.1 \%$ of the kimberlite is calculated to be lost at the rougher stage. Table II and Figure 8 show the results for the scavenger stage. The average kimberlite recovery was calculated to be $99.8 \%$ and the average waste removal was calculated to be $93.1 \%$.

The results clearly indicate that the introduction of a scavenger stage improves the separation efficiency and minimizes the potential for diamond loss. It is also seen that the kimberlite recovery decreases at a low classifier sensitivity. This is due to the fact that low classifier sensitivity reduces the aggressiveness of the machine with respect to its ejecting potential. In both the rougher and scavenger stage the kimberlite recovery was calculated to be above $95 \%$, which clearly indicates that the COLOR/NIR sorter is able to discriminate between the CDM kimberlitic and waste rocks.

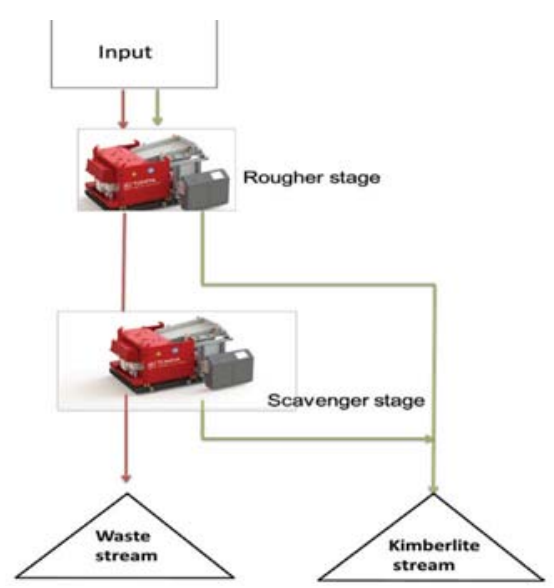

Figure 6-Flow diagram used for the test work (Ketelhodt et al., 2013)

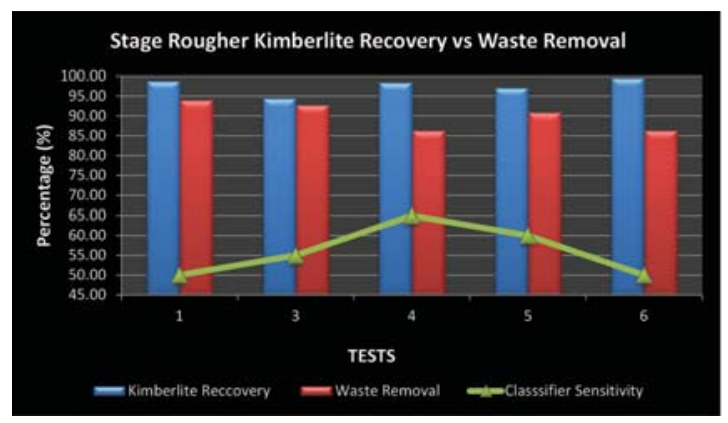

Figure 7-Kimberlite recovery vs waste removal (rougher stage)

\begin{tabular}{|c|c|c|c|c|c|c|c|c|c|c|}
\hline \multicolumn{11}{|c|}{$\begin{array}{l}\text { Table I } \\
\text { Results of rougher stage sorting }\end{array}$} \\
\hline \multirow[t]{2}{*}{ Test } & \multirow{2}{*}{$\begin{array}{c}\text { Classifier sensitivity } \\
\text { setting (\%) }\end{array}$} & \multirow{2}{*}{ Feed (kg) } & \multirow{2}{*}{$\begin{array}{l}\text { Kimberlite in } \\
\text { feed (kg) }\end{array}$} & \multirow{2}{*}{$\begin{array}{l}\text { Waste in } \\
\text { feed }(\mathrm{kg})\end{array}$} & \multicolumn{2}{|c|}{ Kimberlite lost } & \multicolumn{2}{|c|}{ Kimberlite recovery } & \multicolumn{2}{|c|}{ Waste romoval } \\
\hline & & & & & Roug. (\%) & Scav. (\%) & (kg) & (\%) & (kg) & $(\%)$ \\
\hline 1 & 50 & 958.0 & 457.1 & 509.9 & 1.03 & - & 452.0 & 98.89 & 480.0 & 94.13 \\
\hline 3 & 55 & 1220.0 & 616.5 & 603.5 & 5.64 & & -583.0 & 94.57 & 560.5 & 92.87 \\
\hline 4 & 65 & 1149.0 & 600.0 & 549.0 & 1.76 & - & 591.5 & 98.58 & 474.5 & 86.43 \\
\hline 5 & 60 & 1376.0 & 685.0 & 691.0 & 2.93 & - & 666.0 & 97.23 & 629.0 & 91.02 \\
\hline 6 & 50 & 1189.0 & 581.1 & 607.9 & 4.28 & - & 579.1 & 99.66 & 525.5 & 86.44 \\
\hline
\end{tabular}

Table II

Results of scavenger stage sorting

\begin{tabular}{|c|c|c|c|c|c|c|c|c|c|c|}
\hline \multirow[t]{2}{*}{ Test } & \multirow{2}{*}{$\begin{array}{c}\text { Classifier sensitivity } \\
\text { setting (kg) }\end{array}$} & \multirow[t]{2}{*}{ Feed $(\mathrm{kg})$} & \multirow{2}{*}{$\begin{array}{l}\text { Kimberlite in } \\
\text { feed (kg) }\end{array}$} & \multirow{2}{*}{$\begin{array}{l}\text { Waste in } \\
\text { feed }(\mathrm{kg})\end{array}$} & \multicolumn{2}{|c|}{ Kimberlite lost } & \multicolumn{2}{|c|}{ Kimberlite recovery } & \multicolumn{2}{|c|}{ Waste romoval } \\
\hline & & & & & Roug. (\%) & Scav. (\%) & (kg) & (\%) & (kg) & $(\%)$ \\
\hline 2 & 45 & 1268.0 & 589.0 & 679.0 & 5.87 & 0.24 & 587.5 & 99.75 & 622.0 & 91.61 \\
\hline 7 & 45 & 1047.0 & 535.2 & 511.8 & 4.83 & 0.34 & 533.6 & 99.69 & 473.4 & 92.50 \\
\hline 8 & 50 & 992.0 & 505.8 & 486.2 & 6.34 & 0.22 & 504.8 & 99.80 & 463.0 & 95.23 \\
\hline
\end{tabular}




\section{Separation of kimberlite from waste rocks using sensor-based sorting}

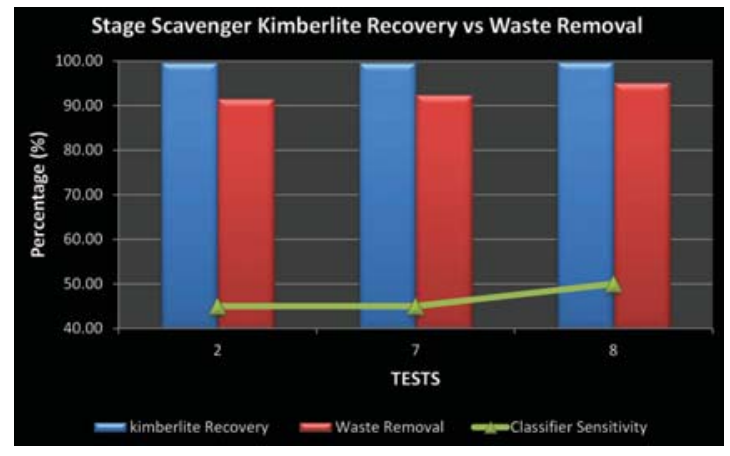

Figure 8-Kimberlite recovery vs waste removal (scavenger stage)

Figure 9 compares the kimberlite loss in the rougher and scavenger stages against the target kimberlite loss of $5 \%$. The kimberlite lost to the waste stream was monitored to prevent the risk of diamond loss.

There is a relatively high loss of the kimberlite ore when using only a rougher stage. However, introducing the scavenger stage minimized the risk of kimberlite loss to an average of $0.3 \%$. The kimberlite lost was above target for tests 2,3 , and 8 because the agressiveness of the machine was kept low.

\section{Pilot plant production}

The feed to the pilot plant was the discharge from the scrubber, screened to $-70+35 \mathrm{~mm}$ size. The main goal of the sorting in this case was to preconcentrate the $-70+35 \mathrm{~mm}$ material prior to the DMS process. A lower waste content in the DMS feed would reduce the impact of near-density waste material on the cyclone dynamics; with the benefit of the reduction of waste material reporting to the DMS concentrate, which could have a detrimental impact on the subsequent Xray sorting processes. The pilot plant was run from September 2014 to April 2015. The commissioning process was complete within a month. Figure 10 illustrates the pilot plant flow sheet, where only the single pass configuration was implemented.

\section{Pilot plant results}

Figure 11 shows the average tons treated through the pilot plant for a period of 6 months (November 2014 to -April 2015) when the plant was running at full production.

The total tonnage fed to the pilot plant was lower than the design tonnage of $50000 \mathrm{t} /$ month, due to the fact that the availability and utilization of the pilot plant was lower than expected. The availability of the pilot plant was critical for successful assessment of the sensor-based sorter and economic evaluation.

Throughout the duration of the project the tailings stream was sampled to monitor the average kimberlite loss.

Kimberlite loss is an indication of potential diamond loss, and should be kept at a minimum. The acceptable kimberlite loss was set at a target of below $5 \%$.

Figure 12 shows the kimberlite loss during the pilot plant campaign. It was possible to keep the kimberlite loss below $5 \%$ for several months, but in January 2015 a high loss of ore occurred. It was decided to stop the sorter until the problem was found and rectified. The sorter was found to have lost programming and had to be re-programmed with preclassified samples. It was also realized that the kimberlite loss was above target when the screen sprays were blocked and the feed coated with mud. After the problem was rectified

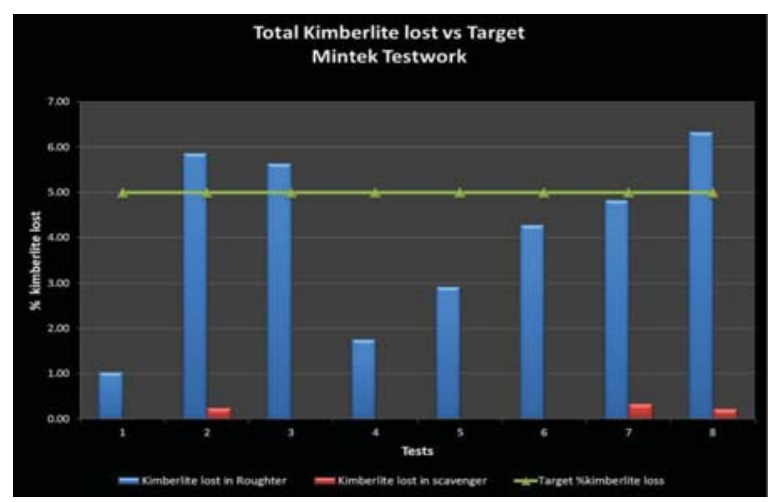

Figure 9-Kimberlite lost to the waste stream vs target loss

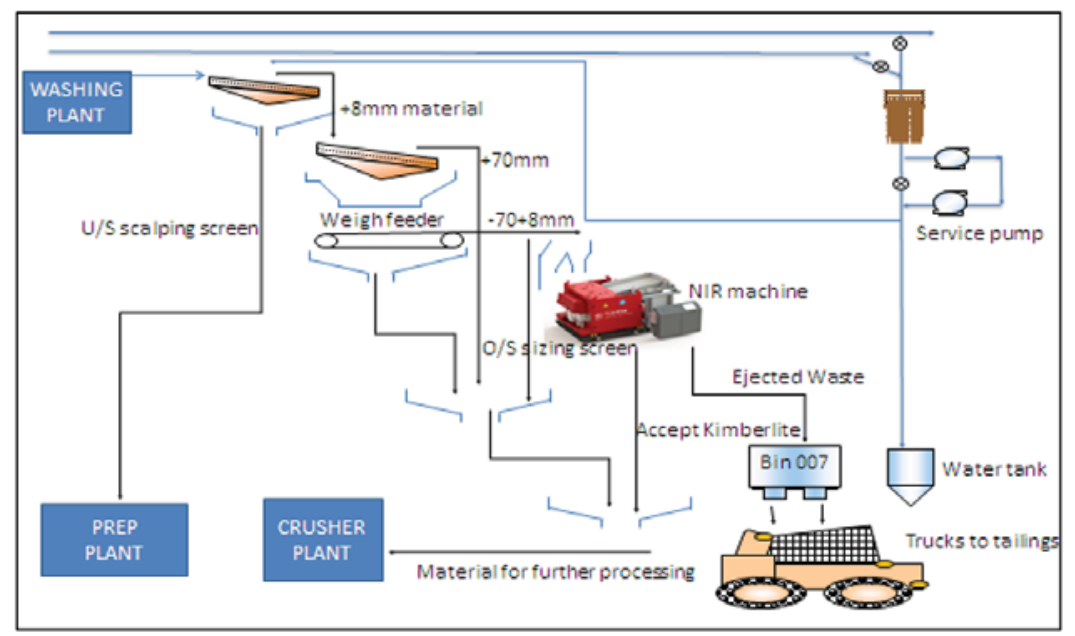

Figure 10-Pilot plant flow sheet 


\section{Separation of kimberlite from waste rocks using sensor-based sorting}



Figure 11-Tonnages treated through the pilot plant

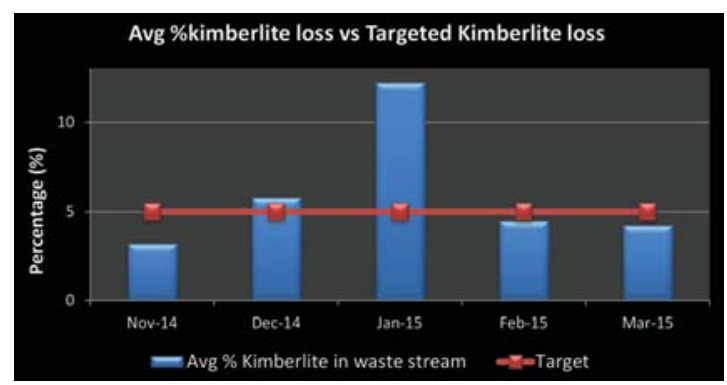

Figure 12-Kimberlite losses to the tailings vs target kimberlite loss

the kimberlite loss was acceptable, as can be seen in Figure 12 .

\section{Conclusion}

Based on the test work, the COLOR/NIR sorter is generally a good tool to separate Cullinan kimberlite from waste rocks. The introduction of a scavenger stage will improve the kimberlite recovery and also minimize diamond loss. The pilot plant test work results were not consistent since the sensing technology is based on the surface properties of the material, hence the feed needs to be clean and free of dust or mud prior to sorting. However, this is not always the case in a production environment, particularly for kimberlite ores, which have a high content of clay material. Due to the risk of diamond loss as a function of kimberlite lost, it is recommended that a scavenger stage be implemented in further kimberlite preconcentration processes using the same sorting system.

\section{Acknowledgements}

The author wishes to express her gratitude to Cullinan Diamond Mine (Pty) Ltd for the opportunity and funding for the project. The deepest thanks are extended to my mentor and supervisor for their guidance and technical input, and to the CDM laboratory personnel for their assistance during the test work and analysis. The inputs from Mintek and Tomra Sorting (Pty) Ltd, South Africa, are also acknowledged.

\section{References}

ASD Inc. 2010. Fieldspec3 User Manual,

http://support.asdi.com/document/documents.aspx [Accessed 28 May 2015].
Barletr, P.J. 1998. Premier Mine. Proceedings of the 7th International Kimberlite Conference, Cape Town. pp. 39-49.

BERRY, L.G. and MASON, B. 1959. Mineralogy: Concepts, Description and Determinants. Springer, San Franciso. pp. 296-298.

CHADwick, J. 2008. Process progress. International Mining, May 2008 pp. 24-40.

CHRISTON, J. 2014. Sensor based sorting technology implementation in the mining and mineral processing. Lund University, Sweden.

COMMODASTUlTRASORT. 2009. Sorters reduce mining costs and increase profits. pp. 34-36.

DALM, M. 2012. TA3690 - Project on sensor based sorting of coppermolybdenum ore. pp. 1-4.

Death, D.L., Cunningham, A.P., and Pollard, L.J. 2009. Multi-element and mineralogical analysis of mineral ores using laser breakdown spectroscopy. Spectrochimica Acta Part B. Atomic Spectroscopy, vol. 64, no. 10. pp. 1048-1058.

Harmon, R.S., DeLucia, F.C., McManus, C.E., McMillan, N.J., Jenkins, T.F., WALSH, M.E., and Miziolek, A. 2006. Laser-induced breakdown spectroscopy - an emerging chemical sensor technology for real-time fieldportable, geochemical, mineralogical, and environmental applications. Applied Geochemistry, vol. 21, no. 5. pp. 730-747.

Hollas, J.M. 2004. Modern Spectroscopy. 5th edn. Wiley. Chapters 1-3.

RobBen, M., Wotruba, H., Balthasa, D., and Rehimann, V. 2009, NIR spectral imaging in the mineral processing industry. RWTH Aachen University, Germany. pp. 2-5.

RoBBinson, D.N. 1973. Magnetite-serpentine-calcite dykes at Premier Mine and aspects of their relationship to kimberlite and to carbonatite of alkali carbonatite complexes. Physics and Chemistry of the Earth, vol. 9. pp. 61-70.

SALTER, J.D. and WyATT, N.P.G. 1991. Sorting in the mineral industry: past, present and future. Minerals Engineering, vol. 4, no. 7. p. 779-796.

Sassos, M.P. 1985. Mineral sorters. Engineering and Mining Journal, vol. 186 , no. 6. pp 68-72.

SmiTH, C.B. 1983. Pb, Sr, and Nd isotopic evidence for sources of southern African Cretaceous kimberlites. Nature, vol. 304, no. 5921. pp. 51-54

Tong, Y, 2009. Technical amenability study of laboratory scale sensor-based ore sorting on a Mississippi Valley type lead-zinc ore, MASc thesis, Department of Mining Engineering, University of British Columbia. pp. 19-20.

WAGNER, P.A. 1914. The Diamond Fields of South Africa. Transvaal Leader, Johannesburg. 347 pp.

Westhyzen, P., Bouwer, W., and JAkins, A. 2013. Current trends in the development of new or optimization of existing diamond processing plants, with the focus on beneficiation. Journal of the Southern African Institute of Mining and Metallurgy, vol. 114. pp. 539-545.

Wills, B.A. and Napier-MunN, T. 2006. Mineral Processing Technology. 7th edn. Elsevier Science \& Technology, Brisbane. Chapter 14, pp. 372-377. 